\section{A Phase 2 Study of Bortezomib in Relapsed, Refractory Myeloma}

\author{
Paul G. Richardson, M.D., Bart Barlogie, M.D., Ph.D., James Berenson, M.D., \\ Seema Singhal, M.D., Sundar Jagannath, M.D., David Irwin, M.D., \\ S. Vincent Rajkumar, M.D., Gordan Srkalovic, M.D., Melissa Alsina, M.D., \\ Raymond Alexanian, M.D., David Siegel, M.D., Robert Z. Orlowski, M.D., \\ David Kuter, M.D., Ph.D., Steven A. Limentani, M.D., \\ Stephanie Lee, M.D., Teru Hideshima, M.D., Ph.D., \\ Dixie-Lee Esseltine, M.D., Michael Kauffman, M.D., Ph.D., Julian Adams, Ph.D., \\ David P. Schenkein, M.D., and Kenneth C. Anderson, M.D.
}

\section{ABSTRACT}

BACKGROUND

Bortezomib, a boronic acid dipeptide, is a novel proteasome inhibitor that has been shown in preclinical and phase 1 studies to have antimyeloma activity.

\section{METHODS}

In this multicenter, open-label, nonrandomized, phase 2 trial, we enrolled 202 patients with relapsed myeloma that was refractory to the therapy they had received most recently. Patients received $1.3 \mathrm{mg}$ of bortezomib per square meter of body-surface area twice weekly for 2 weeks, followed by 1 week without treatment, for up to eight cycles (24 weeks). In patients with a suboptimal response, oral dexamethasone (20 mg daily, on the day of and the day after bortezomib administration) was added to the regimen. The response was evaluated according to the criteria of the European Group for Blood and Marrow Transplantation and confirmed by an independent review committee.

RESULTS

Of 193 patients who could be evaluated, 92 percent had been treated with three or more of the major classes of agents for myeloma, and in 91 percent, the myeloma was refractory to the therapy received most recently. The rate of response to bortezomib was 35 percent, and those with a response included 7 patients in whom myeloma protein became undetectable and 12 in whom myeloma protein was detectable only by immunofixation. The median overall survival was 16 months, with a median duration of response of 12 months. Grade 3 adverse events included thrombocytopenia (in 28 percent of patients), fatigue (in 12 percent), peripheral neuropathy (in 12 percent), and neutropenia (in 11 percent). Grade 4 events occurred in 14 percent of patients.

\section{CONCLUSIONS}

Bortezomib, a member of a new class of anticancer drugs, is active in patients with relapsed multiple myeloma that is refractory to conventional chemotherapy.
From the Dana-Farber Cancer Institute, Boston (P.G.R., S.L., T.H., K.C.A.); University of Arkansas, Little Rock (B.B.); CedarsSinai Medical Center, Los Angeles (J.B.); Northwestern University Medical Center, Chicago (S.S.); St. Vincent's Catholic Medical Center, New York (S.J.); Alta Bates Cancer Center, Berkeley, Calif. (D.I.); Mayo Clinic, Rochester, Minn. (S.V.R.); Cleveland Clinic Foundation, Cleveland (G.S.); H. Lee Moffitt Cancer Center, Tampa, Fla. (M.A.); M.D. Anderson Cancer Center, Houston (R.A.); Carol G. Simon Cancer Center, Morristown, N.J. (D.S.); University of North Carolina, Chapel Hill (R.Z.O.); Massachusetts General Hospital, Boston (D.K.); Charlotte Medical Clinic, Charlotte, N.C. (S.A.L.); and Millennium Pharmaceuticals, Cambridge, Mass. (D.-L.E., M.K., J.A., D.P.S.). Address reprint requests to Dr. Richardson at the Department of Adult Oncology, Dana-Farber Cancer Institute, 44 Binney St., Dana 1B12, Boston, MA 02115, or at paul_richardson@dfci.harvard.edu.

N Engl J Med 2003;348:2609-17.

Copyright $\odot 2003$ Massachusetts Medical Society. 
M

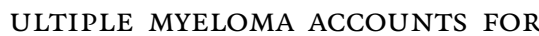
approximately 14,600 new cases of cancer and 10,800 deaths annually in the United States. ${ }^{1}$ Although conventional chemotherapy and high-dose therapy ${ }^{2}$ with hematopoietic stem-cell rescue can prolong survival, few, if any, patients are cured. Salvage therapies for relapsed disease are equally disappointing, $, 3,4$ and although thalidomide has shown promise, ${ }^{5,6}$ new treatments are urgently needed.

We report here the effects of bortezomib (Velcade [Millenium Pharmaceuticals], formerly known as PS-341), a selective inhibitor of the proteasome, in patients with multiple myeloma. The proteasome is a multi-enzyme complex that is present in all cells. It degrades proteins that regulate cell-cycle progres$\operatorname{sion}^{7-12}$ and causes proteolysis of the endogenous inhibitor of nuclear factor- $\kappa \mathrm{B}(\mathrm{NF}-\kappa \mathrm{B})$, I $\kappa \mathrm{B}$. Degradation of $\mathrm{I} \kappa \mathrm{B}$ by proteasomes activates NF- $\kappa \mathrm{B}$, which, in turn, up-regulates the transcription of proteins that promote cell survival, stimulate growth, and reduce susceptibility to apoptosis. NF- $\kappa \mathrm{B}$ activation also induces drug resistance in myeloma cells and up-regulates the expression of adhesion molecules involved in the resistance of myeloma cells to drugs. In addition, it modulates the secretion by bone marrow stromal cells of cytokines that mediate the growth, survival, and migration of myeloma cells. ${ }^{13-19}$

Bortezomib, a boronic acid dipeptide and a potent, selective, and reversible inhibitor of the proteasome, is, to our knowledge, the first agent in this class of small molecules to enter clinical trials. It is administered intravenously in 3 to 5 seconds, rapidly disappears from the vascular compartment, and inhibits the proteasome, with a biologic half-life of approximately 24 hours. ${ }^{20}$ Bortezomib has antitumor activity in a variety of in vitro and in vivo models of tumors, either alone ${ }^{21-25}$ or in combination with common chemotherapeutic agents ${ }^{26-30}$ or radiation. ${ }^{31,32}$ It induces apoptosis in myeloma-cell lines and in myeloma cells from patients whose disease is resistant to conventional therapies. Bortezomib also down-regulates the expression of adhesion molecules by myeloma cells and bone marrow stromal cells, inhibits cell-adhesion-mediated drug resistance, and decreases transcription and secretion of cytokines in the bone marrow milieu. ${ }^{14,22,33,34}$ Its molecular mechanisms entail more than NF- $\kappa \mathrm{B}$ inhibition, ${ }^{33,34}$ and in vitro, it enhances the antimyeloma activity of both conventional and novel chemotherapeutic agents. ${ }^{19,33,35,36}$ In an in vivo study, bortezomib inhibited tumor-cell growth and prolonged survival of mice carrying grafts of human myeloma cells. ${ }^{21}$

In a phase 1 study in patients with advanced hematologic cancer, bortezomib showed activity in nine patients with myeloma. ${ }^{37}$ This observation, along with preclinical evidence of antimyeloma activity, provided the rationale for our open-label phase 2 study of bortezomib for the treatment of relapsed, refractory myeloma.

\section{METHODS}

\section{PATIENTS}

Study patients were at least 18 years of age, with relapsed, refractory myeloma and a life expectancy of more than three months. Measurable disease was defined as a monoclonal immunoglobulin concentration on serum electrophoresis of at least $1 \mathrm{~g}$ of IgG per deciliter or $0.5 \mathrm{~g}$ of IgA per deciliter or urinary excretion of at least $200 \mathrm{mg}$ of monoclonal light chain per 24 hours; patients with nonsecretory or oligosecretory myeloma had other evidence of measurable disease. All patients had had a relapse after undergoing conventional chemotherapy, and their myeloma was refractory to salvage chemotherapy, as defined by progression during treatment or within 60 days after the completion of treatment.

Eligibility criteria included a Karnofsky performance-status score of at least 60 , a serum concentration of aspartate aminotransferase or alanine aminotransferase no higher than three times the upper limit of the normal range, a serum total bilirubin concentration no higher than twice the upper limit of the normal range, a measured or calculated creatinine clearance of more than $10 \mathrm{ml}$ per minute, a platelet count of at least 30,000 per cubic millimeter, a hemoglobin concentration of at least $8 \mathrm{~g}$ per deciliter, and an absolute neutrophil count of at least 500 per cubic millimeter. Patients agreed to use contraception, and women had a pregnancy test that was confirmed to be negative before enrollment.

All patients gave written informed consent before entering the study, which was performed in accordance with the Declaration of Helsinki; approval was obtained from the institutional review board at each of the participating centers.

\section{STUDY DESIGN AND TREATMENT}

Patients received bortezomib (1.3 mg per square meter of body-surface area) as an intravenous bolus (taking three to five seconds to administer) twice 
weekly for 2 weeks, on days 1, 4, 8, and 11 in a 21-day cycle. Patients with progressive disease after two cycles or stable disease after four cycles were eligible to receive $20 \mathrm{mg}$ of oral dexamethasone on the day of and the day after each dose of bortezomib. Participants received up to eight cycles of bortezomib; those in whom there was continuing clinical benefit could receive additional treatment with bortezomib in a separate extension study. Treatment was withheld from patients with grade 3 or worse nonhematologic toxic effects or grade 4 hematologic toxic effects until the effects had diminished to grade 1 or better; after resolution, treatment was resumed at a dose of $1.0 \mathrm{mg}$ per square meter. Further reduction to $0.7 \mathrm{mg}$ per square meter was allowed, but lower doses were not permitted.

The investigators and representatives from Millennium Pharmaceuticals designed the study. The data were collected and analyzed by medical and statistical representatives from Millennium in conjunction with the investigators. All investigators had access to the primary data and participated in writing this article. All participating institutions received grant support for the conduct of the study.

\section{ASSESSMENT OF EFFICACY}

The primary end point was the overall rate of response to bortezomib (including complete responses, partial responses, and minimal responses). Secondary end points were the time to progression during treatment with bortezomib alone or during treatment with bortezomib in combination with dexamethasone, survival, safety, the rate of response to bortezomib in combination with dexamethasone, and the quality of life. Evaluation of responses was performed between days 15 and 18 of cycles 2, 4, 6, and 8 . Responses were assessed by an independent review committee according to the criteria of the European Group for Blood and Marrow Transplantation (EBMT). ${ }^{38}$

A complete response was defined by a negative immunofixation test for myeloma protein in serum and urine, the absence of soft-tissue plasmacytomas, a normal serum calcium concentration, stable skeletal disease, and less than 5 percent plasma cells in the marrow in two specimens obtained six weeks apart. Patients with insufficient data for an assessment of efficacy were considered to have had a treatment failure. A near-complete (immunofixationpositive) response was defined by the absence of myeloma protein on electrophoresis, independent of the immunofixation-test status, stable bone disease, and a normal serum calcium concentration.

Time-to-event analysis was performed according to the Kaplan-Meier method. The time to the first response was defined as the time from the initial administration of bortezomib to the first evidence of a confirmed response. The duration of a response was defined as the time from the achievement of a response to progression. The time to disease progression was defined as the time from the initial administration of bortezomib to disease progression, without censoring of data for the addition of dexamethasone or additional treatment with bortezomib received during the extension study. For the analysis of treatment with bortezomib alone, data for patients who received dexamethasone in combination with bortezomib, additional bortezomib in the extension study, or alternative therapy, as well as for those patients who died without a reported date of progression, were censored at the last evaluation before they began receiving additional therapy or died.

\section{ASSESSMENT OF SAFETY AND OTHER SECONDARY} END POINTS

Adverse events were assessed at each visit and graded according to the National Cancer Institute Common Toxicity Criteria (version 2.0) from the first dose until 20 days after the last dose of bortezomib. A neurologist performed a complete neurologic evaluation during initial screening, during treatment as needed, and at the end of treatment. Quality of life was assessed with the use of the core quality-of-life questionnaire (QLQ-C30), and the module on multiple myeloma (QLQ-MY24) of the European Organization for Research and Treatment of Cancer, the neurotoxicity subscale of the Gynecologic Oncology Group's Functional Assessment of Cancer Therapy (FACT/GOG-NTX), and the fatigue subscale of the Functional Assessment of Chronic Illness Therapy. These assessments were performed on day 1 of cycles $1,3,5$, and 7 , as well as at the end of the study. The time to progression during the last course of treatment before study entry was calculated on the basis of the date of relapse recorded by the investigator. Paraprotein levels and skeletal radiographs were reviewed to verify the progression of myeloma during receipt of the last course of treatment.

\section{STATISTICAL ANALYSIS}

The statistical analysis specified that a lower limit of the two-sided 90 percent confidence interval for the 
overall response rate that exceeded 10 percent would be considered to be evidence of significant activity. No formal comparisons of bortezomib alone with bortezomib plus dexamethasone were planned or conducted. We performed univariate analyses using Fisher's exact test for categorical factors and logistic regression for continuous factors. In addition, we conducted a multivariate logistic-regression analysis using all prognostic factors in the model and then using a stepwise selection method in which terms were retained if they reached the 0.20 level of significance. All descriptive statistical analyses were performed with the use of SAS statistical software (version 8.2, SAS Institute). Analysis of the time to progression of disease during study treatment and during the last course of treatment was performed with the use of the fixed-effect partial-likelihood

\begin{tabular}{|c|c|}
\hline Characteristic & Value \\
\hline $\begin{array}{l}\text { Age }-y r \\
\text { Mean } \\
\text { Range }\end{array}$ & $\begin{array}{c}60 \\
34-84\end{array}$ \\
\hline Durie-Salmon stage III multiple myeloma — \% & 72 \\
\hline $\begin{array}{l}\text { Time since diagnosis - yr } \\
\text { Median } \\
\text { Range }\end{array}$ & $\begin{array}{c}4.0 \\
1.0-18.0\end{array}$ \\
\hline Karnofsky performance score $\leq 70-$ no./total no. (\%) & $40 / 196(20)$ \\
\hline $\begin{array}{l}\text { Serum beta }{ }_{2} \text {-microglobulin concentration } \\
\text { Median - mg/liter } \\
\text { Range - mg/liter } \\
\quad \geq 4 \mathrm{mg} / \text { liter - no./total no. (\%) }\end{array}$ & $\begin{array}{c}3.5 \\
0.1-133.0 \\
81 / 187(43)\end{array}$ \\
\hline $\begin{array}{l}\text { Hemoglobin concentration } \\
\quad \text { Median }-\mathrm{g} / \mathrm{dl} \\
\text { Range }-\mathrm{g} / \mathrm{dl} \\
<10 \mathrm{~g} / \mathrm{dl}-\text { no./total no. (\%) }\end{array}$ & $\begin{array}{c}10.2 \\
5.4-14.6 \\
88 / 202(44)\end{array}$ \\
\hline $\begin{array}{l}\text { Platelet count } \\
\quad \text { Median - per } \mathrm{mm}^{3} \\
\text { Range - per } \mathrm{mm}^{3} \\
<75,000 \text { per } \mathrm{mm}^{3}-\text { no./total no. (\%) }\end{array}$ & $\begin{array}{c}162,000 \\
11,000-479,000 \\
42 / 202(21)\end{array}$ \\
\hline $\begin{array}{l}\text { Cytogenetic abnormalities - no./total no. (\%)* } \\
\text { Deletion of chromosome } 13\end{array}$ & $\begin{array}{l}60 / 172(35) \\
26 / 172(15)\end{array}$ \\
\hline $\begin{array}{l}\text { Previous therapy — no./total no. (\%) } \\
\text { Any corticosteroid } \\
\text { Any alkylating agent } \\
\text { Any anthracycline } \\
\text { Thalidomide } \\
\text { Stem-cell transplant }\end{array}$ & $\begin{array}{l}201 / 202(100) \\
186 / 202(92) \\
163 / 202(81) \\
168 / 202(83) \\
129 / 202(64)\end{array}$ \\
\hline
\end{tabular}

* Data are from standard cytogenetic analysis in 147 patients (85 percent), from fluorescence in situ hybridization alone in 18 patients (10 percent), and from analyses by other techniques in 7 patients. method. ${ }^{39,40}$ An analysis of survival among patients who had a response as compared with patients who did not have a response was performed with the use of the landmark method at the end of cycle 2.41

\section{RESULTS}

\section{PATIENTS AND TREATMENT}

From February to December 2001, 14 centers enrolled 202 patients, 193 of whom could be evaluated. Table 1 shows selected characteristics of all 202 patients. Most ( 84 percent) had IgG or IgA myeloma and advanced disease at diagnosis, 20 percent had a Karnofsky performance-status score of 70 or less, and 80 percent had symptoms of peripheral neuropathy at enrollment. The mean age was 60 years; 81 percent of the patients were white, 10 percent were black, and 60 percent were men. Of the 193 patients who could be evaluated, 178 had previously been treated with three or more of the major classes of agents for myeloma (Table 1), and the median number of previous therapies was 6 (range, 2 to 15). The remaining 15 had received either two of the major classes of agents or a stem-cell transplant.

The median duration of treatment with bortezomib was 3.8 months; 60 percent of patients completed at least four cycles of therapy, and 39 percent received eight cycles. Of the 202 enrolled patients, 54 (27 percent) discontinued treatment early because of progressive disease, and 45 ( 22 percent) discontinued treatment early because of adverse events; more than 90 percent of these 99 patients had not had a response to bortezomib.

\section{EFFICACY}

Of the 193 patients with measurable disease, 67 (35 percent) had a complete, partial, or minimal response to bortezomib alone (Table 2). Nineteen patients had a complete or near-complete response. The myeloma protein became undetectable by both electrophoresis and immunofixation in 7 of these 19 patients; in the remaining 12 patients, the myeloma protein became undetectable by electrophoresis, but the immunofixation test remained positive. For 12 of the 19 patients with a complete response, the response to bortezomib was the best response they had had to any therapy. The patients in whom a complete response was achieved were similar to the entire group with respect to the extent of previous treatment ( 95 percent had received at least three major classes of drugs). Moreover, in 89 percent of 
patients with a complete response, disease had been refractory to the last therapy received. In an additional 24 percent of patients, the disease became stable. An analysis of maximal myeloma-protein responses without the use of the EBMT criteria revealed a reduction of at least 50 percent in 37 percent of the patients, a reduction of at least 25 percent in 48 percent of the patients, and a response ranging from a 25 percent reduction to a 25 percent increase in 22 percent of the patients.

The median time to a first response was 1.3 months. The median time to progression of disease among all 202 patients while they were receiving bortezomib alone was 7 months ( 6.6 months without censoring of the data for the addition of dexamethasone or additional treatment with bortezomib in the extension study), as compared with 3 months during the last treatment before enrollment $(\mathrm{P}=0.01$ by the fixed-effect partial-likelihood method) (Fig. 1A). The median time to progression among patients with a complete or partial response to bortezomib alone was 13 months (12.5 months without censoring of data for the addition of dexamethasone or additional treatment with bortezomib in the extension study).

The median duration of the response among the 67 patients with a complete, partial, or minimal response to bortezomib alone was 12 months (11.4 months without censoring of data for the addition of dexamethasone or additional bortezomib in the extension study) (range, 1.3 to more than 16.7 months) (Fig. 1B); the median duration of the response among the 19 patients with a complete or near-complete response was 15 months (with patients who received bortezomib in the extension study included in the analysis). Median survival among all 202 patients was 16 months (Fig. 1C). According to a landmark analysis, achievement of a complete or partial response to bortezomib alone after two cycles was associated with significantly longer survival than that in all other patients $(\mathrm{P}=$ 0.007) (Fig. 1D).

Other secondary end points included additional measures of clinical benefit. Among patients with a complete or partial response, 89 percent had a maximal hemoglobin increase of at least $1 \mathrm{~g}$ per deciliter, and 72 percent had a maximal hemoglobin increase of at least $2 \mathrm{~g}$ per deciliter. None of the patients with a complete or partial response needed transfusions after cycle 4 . Responses were also associated with increases in the platelet count, levels of normal immunoglobulins, and Karnofsky per-

\begin{tabular}{|lc|}
\hline $\begin{array}{l}\text { Table 2. Responses to Bortezomib Monotherapy } \\
\text { among } 193 \text { Patients. }\end{array}$ & $\begin{array}{c}\text { No. of } \\
\text { Patients (\%) }\end{array}$ \\
\hline Category of Response & $67(35)$ \\
Any response & $53(27)$ \\
Complete or partial response & $19(10)$ \\
$\begin{array}{l}\text { Complete or near-complete response } \\
\text { Negative on immunofixation testing }\end{array}$ & $7(4)$ \\
$\quad$ Positive on immunofixation testing & $12(6)$ \\
Partial response & $34(18)$ \\
Minimal response & $14(7)$ \\
No change & $46(24)$ \\
\hline
\end{tabular}

formance-status scores (see Supplementary Appendixes 1 and 2, available with the full text of this article at http://www.nejm.org). Analysis of the quality of life among 143 patients revealed maximal improvements in the mean global quality-of-life score and disease symptoms, including pain and fatigue. Patients with a complete or partial response also had a general improvement in global and physicaldomain scores on the QLQ-C30, as well as a decrease in the severity of symptoms of disease, pain, and fatigue (see Supplementary Appendix 3, available with the full text of this article at http://www. nejm.org).

Seventy-eight patients who had either stable or progressive disease while receiving bortezomib alone subsequently received dexamethasone in combination with bortezomib, as specified in the protocol. A total of 74 patients could be evaluated for a response to this combination, and 13 of these patients (18 percent) had a minimal or partial response. In 6 of these 13 patients, the disease had previously been refractory to corticosteroid therapy.

\section{PROGNOSTIC FACTORS}

The response to bortezomib was not influenced by sex, type of myeloma, serum level of beta ${ }_{2}$-microglobulin, or type or number of previous therapies. Older age ( $\geq 65$ years) was loosely associated with a lower response rate (32 percent, vs. 19 percent among younger patients; $\mathrm{P}=0.06$ ). In addition, $\mathrm{pa}-$ tients with more than 50 percent plasma cells in the bone marrow at enrollment had a lower response rate (20 percent, vs. 35 percent among those with a lower percentage of plasma cells in bone marrow; $\mathrm{P}=0.03)$. Responses occurred in patients with ab- 
Figure 1. Responses to Bortezomib.

Panel A shows a Kaplan-Meier plot of time to progression of disease in the 196 patients treated with bortezomib alone or all therapy (bortezomib plus dexamethasone) and the time to progression in the same 196 patients from the beginning of their last therapy to progression before entry into the study. Panel $B$ shows the duration of the response in the 67 patients with a complete, partial, or minimal response to bortezomib alone or to bortezomib plus dexamethasone. Panel $\mathrm{C}$ shows overall survival among all 202 patients. Panel D shows overall survival among the patients with a complete or partial response and among patients without such a response; this analysis was performed according to the landmark method at the end of cycle 2 (day 42).

normalities in chromosome 13 and those without such abnormalities ( 24 percent and 28 percent, respectively). Only age and the percentage of plasma cells in the bone marrow were significant predictors of a response in the multivariate analysis $(\mathrm{P}<0.05)$ (see Supplementary Appendix 4, available with the full text of this article at http://www.nejm.org).

\section{SAFETY}

The most common adverse events were gastrointestinal symptoms, fatigue, thrombocytopenia, and sensory neuropathy (Table 3). Gastrointestinal events were typically mild to moderate and were manageable with routine support. The most common grade 3 adverse events were thrombocytopenia (in 28 percent of patients), fatigue (in 12 percent), neuropathy (in 12 percent), and neutropenia (in 11 percent). Grade 4 events (which occurred in a total of 14 percent of the patients) included thrombocytopenia (in 3 percent) and neutropenia (in 3 percent), with a single case of febrile neutropenia $(<1$ percent). All other grade 4 adverse events occurred in 1 percent or less of the patients, and no patient had grade 4 neuropathy. Among the 33 patients who did not have neuropathy before beginning bortezomib therapy, grade 3 neuropathy developed in 1 and grade 1 or 2 neuropathy developed in 16 . Overall, 12 percent of the patients required a reduction of the dose at least once, and 4 percent of patients discontinued treatment because of peripheral neuropathy.

Drug-related adverse events led to discontinuation of bortezomib therapy in 36 patients (18 percent); no single event accounted for discontinuation in more than 4 percent of patients. Ten patients (5 percent) died within 20 days after the last dose

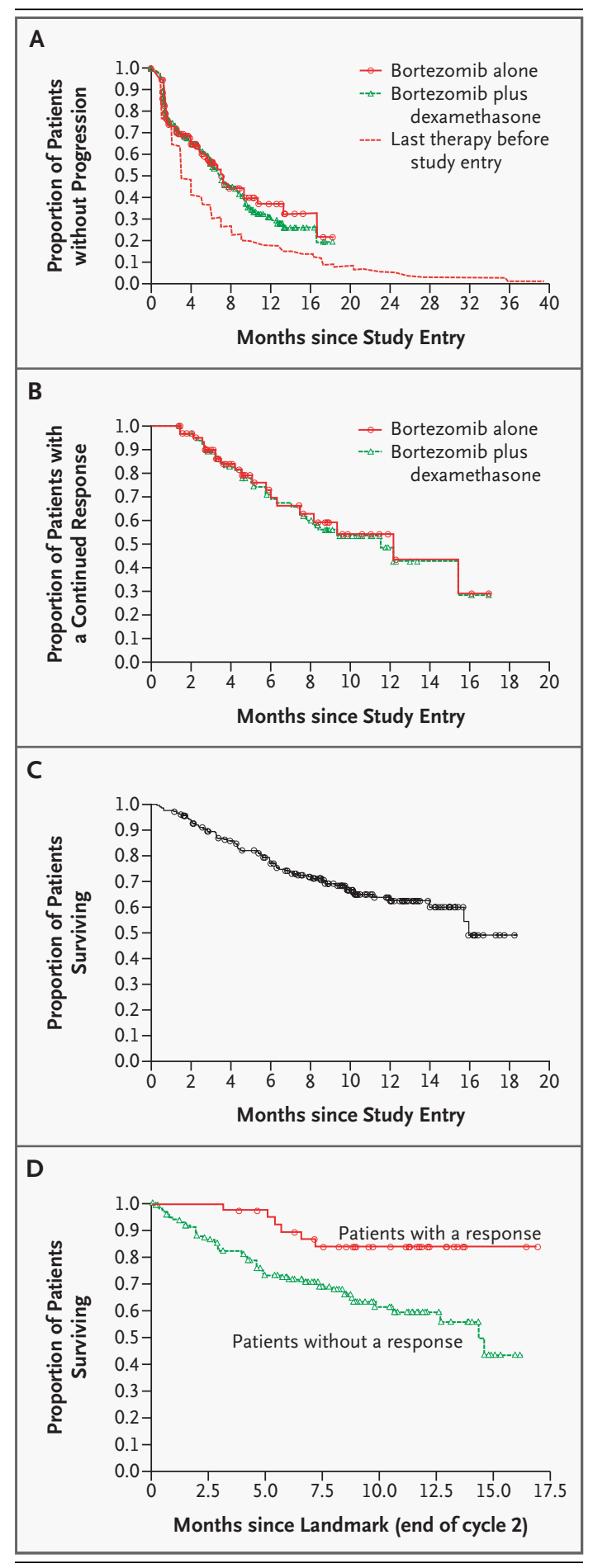

of bortezomib, the majority of them from causes related to progressive myeloma. In two patients ( $<1$ percent), the cause of death was assessed as possibly related to bortezomib treatment. 


\section{I SCUSSION}

In this phase 2 trial, we evaluated the efficacy of bortezomib in patients with relapsed, refractory myeloma. The overall response rate, including complete responses, was 35 percent. The median duration of responses was 12 months, and there was an increase by a factor of two to four in the time to progression with bortezomib therapy as compared with the last therapy patients received before entering the study. Responses were associated with increased hemoglobin levels and decreased transfusion requirements, improved quality of life, and improved levels of normal immunoglobulins.

The rates of major responses to bortezomib in patients with advanced, refractory myeloma are noteworthy. Complete responses are rare in populations of patients with drug-refractory myeloma. Although this trial was uncontrolled, we used several methods to reduce bias in assessing the response to therapy. Each patient was used as his or her own control in the assessment of the time to progression of disease relative to that with the last therapy received before enrollment, and a landmark analysis was performed to demonstrate an association between a response to bortezomib alone and survival. In addition, the median duration of survival among patients without a response (eight months) was within the range (six to nine months) that was expected on the basis of the literature.3,42 It is also noteworthy that responsiveness to bortezomib did not correlate with most of the standard prognostic factors, including the deletion of chromosome 13, which predicts a poor outcome with conventional therapy.

In our trial, 74 of the patients who could be evaluated (37 percent) received dexamethasone with bortezomib after having a suboptimal response to bortezomib alone, and an improved response was achieved in 13 of them. Although it is impossible to determine the contribution of each individual agent, the findings regarding the activity of this combination of agents mirror the preclinical data ${ }^{22}$ and warrant further investigation.

Most adverse events could be managed with the use of standard approaches; the incidence of grade 4 adverse events was relatively low. Severe myelosuppression was uncommon, and grade 4 neutropenia, related febrile neutropenia, and sepsis were rare. Thrombocytopenia, the most common severe adverse event, developed primarily in patients with a low base-line platelet count; it was transient, with

\begin{tabular}{|c|c|c|c|}
\hline Adverse Event & $\begin{array}{l}\text { Bortezomib- } \\
\text { Related } \\
\text { Events }\end{array}$ & $\begin{array}{c}\text { All } \\
\text { Grade } 3 \\
\text { Events } \\
\text { Imber (per }\end{array}$ & $\begin{array}{c}\text { All } \\
\text { Grade } 4 \\
\text { Events }\end{array}$ \\
\hline Nausea & $111(55)$ & $13(6)$ & 0 \\
\hline Diarrhea & $88(44)$ & $14(7)$ & $2(1)$ \\
\hline Fatigue & $83(41)$ & $24(12)$ & 0 \\
\hline Thrombocytopenia & $81(40)$ & $56(28)$ & $6(3)$ \\
\hline Constipation & $33(16)$ & $5(2)$ & 0 \\
\hline Vomiting & $55(27)$ & $16(8)$ & $1(<1)$ \\
\hline Anorexia & $50(25)$ & $5(2)$ & 0 \\
\hline Pyrexia & $45(22)$ & $8(4)$ & 0 \\
\hline Anemia & $42(21)$ & $17(8)$ & 0 \\
\hline Headache & $38(19)$ & $6(3)$ & 0 \\
\hline Peripheral neuropathy & $63(31)$ & $25(12)$ & 0 \\
\hline Pain in limb & $27(13)$ & $14(7)$ & 0 \\
\hline Neutropenia & $38(19)$ & $22(11)$ & $6(3)$ \\
\hline Rash & $31(15)$ & $1(<1)$ & 0 \\
\hline Dizziness (excluding vertigo) & $24(12)$ & $3(1)$ & 0 \\
\hline Weakness & $23(11)$ & $11(5)$ & $1(<1)$ \\
\hline Dehydration & $20(10)$ & $15(7)$ & 0 \\
\hline
\end{tabular}

* Adverse events reported as drug-related are those that were considered by the investigator to be probably or possibly related to the study drug. All $202 \mathrm{pa-}$ tients were included in this analysis.

recovery occurring within the 10-day period during which treatment was suspended, and was not associated with serious bleeding complications. The pattern of the thrombocytopenia is not consistent with the pattern typically observed with conventional chemotherapy.

The most clinically significant adverse event was cumulative, dose-related peripheral sensory neuropathy. New or worsening symptoms or signs of peripheral sensory neuropathy were reported in 34 percent of patients; overall, the incidence of grade 3 peripheral neuropathy was 12 percent, and there were no cases of grade 4 peripheral neuropathy; moreover, complete resolution or improvement of peripheral neuropathy was observed in the majority of patients during the follow-up period. Grade 3 neuropathy developed during treatment in only one 
patient who did not have neuropathy at base line, suggesting that the incidence of neuropathy will be lower in ongoing clinical trials of bortezomib involving patients with earlier-stage myeloma who do not have preexisting neuropathy.

In conclusion, the novel proteasome inhibitor bortezomib induces clinically significant responses, with manageable toxic effects, in patients with relapsed, refractory myeloma. An international, randomized, multicenter phase 3 trial comparing bortezomib with high-dose dexamethasone in patients with relapsed multiple myeloma is ongoing. The results of this trial and other ongoing studies should provide clinical guidance as to how to use this agent in earlier-stage disease.
Supported by Millennium Pharmaceuticals.

Drs. Richardson, Bargolie, and Anderson report having received payment from Millennium for lecturing and serving on its advisory board; Dr. Berenson having served as a paid consultant for and having received lectures fees and grant support from Millennium; Dr. Singhal having received consulting and lecture fees from Millennium and owning stock in the company; Dr. Jagannath having served as a paid consultant to Millennium, Cellular Therapeutics, and Orthobiotech; Dr. Rajkumar having received grants from Millennium and Entremed; Dr. Alexanian having served as a paid consultant to and having received grant support from Millennium; Dr. Siegel having received lecture fees from Millennium and Celgene; Dr. Orlowski having received consultant fees from Millennium; Dr. Limentani having received lecture fees from Aventis and grant support from Aventis, Novartis, GlaxoSmithKline, and Millennium; Dr. Lee having served as a paid consultant for Millennium; Dr. Hideshima having received grant support from Millennium; Dr. Kauffman owning stock in Millennium and is the chief executive officer of Predix Pharmaceuticals; and Drs. Adams, Esseltine, and Schenkein are employees of and report having equity ownership in Millennium.
REFERENCES

1. Cancer facts \& figures 2002. Atlanta: American Cancer Society, 2002.

2. Attal M, Harousseau J-L, Stoppa A-M, et al. A prospective, randomized trial of autologous bone marrow transplantation and chemotherapy in multiple myeloma. N Engl J Med 1996;335:91-7.

3. Blade J, Esteve J. Treatment approaches for relapsing and refractory multiple myeloma. Acta Oncol 2000;39:843-7.

4. Lee $\mathrm{CK}$, Barlogie $B$, Zangari $M$, et al. Transplantation as salvage therapy for highrisk patients with myeloma in relapse. Bone Marrow Transplant 2002;30:873-8.

5. Singhal S, Mehta J, Desikan R, et al. An titumor activity of thalidomide in refractory multiple myeloma. N Engl J Med 1999;341: 1565-71. [Erratum, N Engl J Med 2000;342: 364.]

6. Barlogie B, Desikan R, Eddlemon P, et al. Extended survival in advanced and refractory multiple myeloma after single-agent thalidomide: identification of prognostic factors in a phase 2 study of 169 patients. Blood 2001;98:492-4.

7. Kisselev AF, Goldberg AL. Proteasome inhibitors: from research tools to drug candidates. Chem Biol 2001;8:739-58.

8. Maki CG, Huibregtse JM, Howley PM. In vivo ubiquitination and proteasome-mediated degradation of p53(1). Cancer Res 1996; 56:2649-54

9. Clurman BE, Sheaff RJ, Thress K, Groudine M, Roberts JM. Turnover of cyclin E by the ubiquitin-proteasome pathway is regulated by cdk2 binding and cyclin phosphorylation. Genes Dev 1996;10:1979-90.

10. Tatebe H, Yanagida M. Cut8, essentia for anaphase, controls localization of $26 \mathrm{~S}$ proteasome, facilitating destruction of cyclin and Cut2. Curr Biol 2000;10:1329-38.

11. Cayrol C, Ducommun B. Interaction with cyclin-dependent kinases and PCNA modulates proteasome-dependent degradation of p21. Oncogene 1998;17:2437-44.

12. Pagano M, Tam SW, Theodoras AM, etal.
Role of the ubiquitin-proteasome pathway in regulating abundance of the cyclin-dependent kinase inhibitor p27. Science 1995;269: 682-5.

13. Chauhan D, Uchiyama H, Akbarali $Y$, et al. Multiple myeloma cell adhesion-induced interleukin-6 expression in bone marrow stromal cells involves activation of NF-kappa B. Blood 1996;87:1104-12.

14. Hideshima T, Chauhan D, Schlossman $\mathrm{R}$, Richardson P, Anderson KC. The role of tumor necrosis factor alpha in the pathophysiology of human multiple myeloma: therapeutic applications. Oncogene 2001; 20:4519-27.

15. Hideshima T, Chauhan D, Richardson P, et al. NF-kappa B as a therapeutic target in multiple myeloma. J Biol Chem 2002;277: 16639-47.

16. Mitsiades N, Mitsiades CS, Poulaki V, et al. Biologic sequelae of nuclear factor-kappaB blockade in multiple myeloma: therapeutic applications. Blood 2002;99:4079-86. 17. Mitsiades CS, Mitsiades N, Poulaki V, et al. Activation of NF-kappaB and upregulation of intracellular anti-apoptotic proteins via the IGF-1/Akt signaling in human multiple myeloma cells: therapeutic implications. Oncogene 2002;21:5673-83.

18. Podar K, Tai YT, Lin BK, et al. Vascular endothelial growth factor-induced migration of multiple myeloma cells is associated with beta 1 integrin- and phosphatidylinosito 3-kinase-dependent PKC alpha activation. J Biol Chem 2002;277:7875-81.

19. Hideshima T, Anderson KC. Molecular mechanisms of novel therapeutic approaches for multiple myeloma. Nat Rev Cancer 2002;2:927-37.

20. Nix D, Pien C, Newman R, et al. Clinica development of a proteasome inhibitor, PS-341, for the treatment of cancer. Prog Proc Am Soc Clin Oncol 2001;20:86a. abstract. 21. LeBlanc R, Catley LP, Hideshima T, et al. Proteasome inhibitor PS-341 inhibits human myeloma cell growth in vivo and prolongs survival in a murine model. Cancer Res 2002; 62:4996-5000.

22. Hideshima $T$, Richardson $P$, Chauhan $D$, et al. The proteasome inhibitor PS-341 inhibits growth, induces apoptosis, and overcomes drug resistance in human multiple myeloma cells. Cancer Res 2001;61:3071-6. 23. Adams J, Palombella VJ, Sausville EA, et al. Proteasome inhibitors: a novel class of potent and effective antitumor agents. Cancer Res 1999;59:2615-22.

24. Sunwoo JB, Chen Z, Dong G, et al. Novel proteasome inhibitor PS-341 inhibits activation of nuclear factor-kappa B, cell survival, tumor growth, and angiogenesis in squamous cell carcinoma. Clin Cancer Res 2001; 7:1419-28.

25. Frankel A, Man S, Elliott P, Adams J, Kerbel RS. Lack of multicellular drug resistance observed in human ovarian and prostate carcinoma treated with the proteasome inhibitor PS-341. Clin Cancer Res 2000;6: 3719-28.

26. Pink MM, Pien CS, Worland P, Adams J, Kauffman MG. PS-341 enhances chemotherapeutic effect in human xenograft models. Proc Am Assoc Cancer Res 2002;43:158. abstract.

27. Cusack JC Jr, Liu R, Houston M, et al. Enhanced chemosensitivity to CPT-11 with proteasome inhibitor PS-341: implications for systemic nuclear factor-kappaB inhibition. Cancer Res 2001;61:3535-40.

28. Bold RJ, Virudachalam S, McConkey DJ. Chemosensitization of pancreatic cancer by inhibition of the 26 S proteasome. J Surg Res 2001;100:11-7.

29. Shah SA, Potter MW, McDade TP, et al. $26 S$ proteasome inhibition induces apoptosis and limits growth of human pancreatic cancer. J Cell Biochem 2001;82:110-22.

30. Teicher BA, Ara G, Herbst R, Palombella VJ, Adams J. The proteasome inhibitor PS-341 in cancer therapy. Clin Cancer Res 1999;5:2638-45.

31. Russo SM, TepperJE, Baldwin AS Jr, et al. 
Enhancement of radiosensitivity by proteasome inhibition: implications for a role of NF-kB. Int J Radiat Oncol Biol Phys 2001;50 183-93.

32. Pervan M, PajonkF, Sun JR, Withers HR, McBride WH. Molecular pathways that modify tumor radiation response. Am J Clin Oncol 2001;24:481-5.

33. Mitsiades N, Mitsiades CS, Poulaki V, et al. Molecular sequelae of proteasome inhibition in human multiple myeloma cells Proc Natl Acad Sci U S A 2002;99:14374-9.

34. Hideshima T, Mitsiades C, Akiyama M, et al. Molecular mechanisms mediating antimyeloma activity of proteasome inhibitor PS-341. Blood 2003;101:1530-4.

35. Mitsiades CS, Treon SP, Mitsiades N, et al. TRAIL/Apo2L ligand selectively induces apoptosis and overcomes drug resistance in multiple myeloma: therapeutic applications. Blood 2001;98:795-804.
36. Mitsiades N, Mitsiades CS, Poulaki V, et al. Apoptotic signaling induced by immunomodulatory thalidomide analogs in human multiple myeloma cells: therapeutic implications. Blood 2002;99:4525-30.

37. Orlowski RZ, Stinchcombe TE, Mitchel $\mathrm{BS}$, et al. Phase I trial of the proteasome in hibitor PS-341 in patients with refractory hematologic malignancies. J Clin Oncol 2002; 20:4420-7.

38. Blade J, Samson D, Reece D, et al. Criteria for evaluating disease response and progression in patients with multiple myelom treated by high-dose therapy and haemopoietic stem cell transplantation. Br J Haemato 1998; 102:1115-23.

39. Allison PD. Survival analysis using the SAS system: a practical guide. Cary, N.C.: SAS Institute, 1995.

40. Chamberlain GA. Heterogeneity, omitted variable bias, and duration dependence.
In: Heckman JJ, Singer BS, eds. Longitudina analysis of labor market data. Cambridge, England: Cambridge University Press, 1985. 41. Simon R, Makuch RW. A non-parametric graphical representation of the relationship between survival and the occurrence of an event: application to responder versus non-responder bias. Stat Med 1984;3:35-44. 42. Gertz MA, Kalish LA, Kyle RA, Hahn RG, Tormey DC, Oken MM. Phase III study comparing vincristine, doxorubicin (Adriamycin), and dexamethasone (VAD) chemotherapy with VAD plus recombinant interferon alfa-2 in refractory or relapsed multiple myeloma: an Eastern Cooperative Oncology Group study. Am J Clin Oncol 1995;18:47580.

Copyright (C) 2003 Massachusetts Medical Society.

ELECTRONIC ACCESS TO THE JOURNAL'S CUMULATIVE INDEX

At the Journal's site on the World Wide Web (http://www.nejm.org) you can search an index of all articles published since January 1975 (abstracts 1975-1992, full-text 1993-present). You can search by author, key word, title, type of article, and date. The results will include the citations for the articles plus links to the abstracts of articles published since 1993. For nonsubscribers, time-limited access to single articles and 24-hour site access can also be ordered for a fee through the Internet (http://www.nejm.org). 